\title{
SOFM-based Classification of Soil and Water Conservation Regionalization in Jinyun
}

\author{
Tengfei Shi ${ }^{1,2,3}$, Nan Tian ${ }^{4, *}$, Ran Wang ${ }^{1,2,3}$, Gang Tian ${ }^{1,2,3}$, and Mengyin Chen ${ }^{1,2,3}$ \\ ${ }^{1}$ Zhejiang Guangchuan Engineering Consulting Co. Ltd., Hangzhou, Zhejiang 310020, China \\ ${ }^{2}$ Zhejiang Institute of Hydraulics and Estuary, Hangzhou, Zhejiang 310020, China \\ ${ }^{3}$ Zhejiang Key Laboratory of Water Disaster Prevention and Reduction, Hangzhou 310020, China \\ ${ }^{4}$ Hangzhou Academy of Forestry, Hangzhou, 310022, Zhejiang, China
}

\begin{abstract}
In this paper, 18 towns of Jinyun were analyzed. Natural conditions (average elevation, relative height difference, and gully density), socio-economic status(population density, and per capita disposable income), characteristics of soil erosion (area ratio of soil erosion, area ratio of soil erosion above moderate), and the present state of soil and water conservation, (vegetation coverage) were calculated. Self-organizing Feature Maps (SOFM) was used for soil and water conservation regionalization. Through the analysis of the 18 towns in Jinyun, two first-order classes and five second-order types were identified. The results showed that the classification results were consistent with the actual characteristics, and the feasibility of using SOFM for classification of soil and water conservation regionalization has been demonstrated through this study.
\end{abstract}

\section{Introduction}

The newly revised "Soil and Water Conservation Law" in 2011 clarified the legal status of soil and water conservation planning, and soil and water conservation regionalization, which is one of the basic tasks of the planning, also started simultaneously ${ }^{[1]}$. Regionalization of soil and water is to divide the area into several water and soil conservation areas based on natural conditions, socio-economic conditions, characteristics of soil erosion, and the current status of soil and water conservation, and to adopt a corresponding development direction (or landuse direction), and a layout of measures to prevent soil erosion for each area ${ }^{[2]}$. Therefore, soil and water conservation regionalization is an important basis for scientifically carrying out soil and water conservation work and formulating regional soil and water conservation planning ${ }^{[3]}$, and will effectively guide the soil and water conservation planning and work for an extended period of time ${ }^{[4]}$. It emphasizes the guidance, the general principles, and the direction and approach of soil erosion control. Wang Zhiguo et $\mathrm{al}^{[5]}$ studied soil and water conservation regionalization and its application in China, and provided a long-term guide of the country, while county-level regions still lacked in this regard.

SOFM (Self-Organizing Feature Maps) is a selforganizing feature map network proposed by Kohonen in $1981^{[6-7]}$, which has the ability of topology maintenance and the characteristic of the self-organizing probability distribution and can handle a large number of inaccurate and incomplete ambiguities information, suitable for classifying multidimensional data ${ }^{[8]}$.

Therefore, based on the four categories of indicators, such as natural conditions, socio-economic status, this paper conducts a study on the classification of soil and water conservation regionalization of 18 towns in Jinyun, characteristics of soil erosion, and soil and water conservation status, to provide a new thought and method for the classification of county soil and water conservation regionalization.

\section{Survey of the research area}

Jinyun is located in the south-central part of Zhejiang Province, northeast of Lishui City, and has jurisdiction over 3 streets (Wuyun Street, Xinbi Street, Xiandu Street), 7 towns (Huzhen Town, Xinjian Town, Shuhong Town, Dayang Town, East Du Town, Dongfang Town, Dayuan Town), and 8 townships (Qili Township, Qianlu Township, Sanxi Township, Shuangxikou Township, Rongjiang Township, Huyuan Township, Fangxi Township, Shijian Township). The total land area is $1503.52 \mathrm{~km}^{2}$. The landform types are mainly mountains and hills. The rivers in the territory mainly include Hao Creek, Xinjian Creek, and Yongan Creek, etc. All of them are mountain streams with short sources, rapid flows, large runoff, and low natural water storage capacity. The soil is dominated by red soil and yellow soil, and the vertical zonal distribution is obvious. Soil and water loss in the area is mainly caused by large-scale disordered development of cash fruit-land and disturbance of development of production and

\footnotetext{
* Corresponding author: shitengfei003@163.com
} 
construction projects. Landslides, slope disintegration erosion, and soil and water loss in thin stocked land are also the major types of loss.

\section{Methods}

\subsection{Index system construction}

This paper focuses on natural conditions (average elevation, relative height difference, and gully density, socio-economic status (population density, per capita disposable income), characteristics of soil erosion (area ratio of soil erosion, area ratio of soil erosion above moderate), and the present state of soil and water conservation, (vegetation coverage) and many other indicators are selected as the classification index system. In this study, a total of 18 townships and 8 index data reflecting water and soil conservation conditions were included to form an $18 \times 8$-dimensional data matrix.

\subsection{Data processing}

SOFM is a neural network clustering method. It performs network training without supervision. It discovers and extracts its intrinsic features from a large amount of input data through the self-organization of the network structure. The input data distribution topology map is formed on the network output node weighted vector space, which reflects a certain distribution rule of the input data, and can automatically cluster the input patterns [9]. Due to its unique advantages, the SOFM neural network clustering method is used in many classification studies. Using the SOFM network to classify water and soil conservation regionalization, the process can be summarized as 5 steps ${ }^{[10]}$ :

(1) Initialization. Given a small initial value, choose the neighborhood radius and learning rate.

(2) Input samples, and normalize the weight input vector $\mathrm{X}$.

(3) Find the minimum Euclidean distance and search for the winning neuron.

(4) Modify the connection weight of the selected neuron and the adjacent neuron.

(5) Provide a new input vector and repeat the above learning process until a meaningful map is formed.

Through training, the winning neuron in the final output layer and the weights in its neighborhood approximate the input vectors, and pattern classification is achieved. For the specific algorithm, please refer to the instruction of the neural network toolbox in Matlab software.

\section{Results and analysis}

In this study, a total of 18 townships and 8 index data reflecting soil and water conservation conditions were included, forming an $18 \times 8$-dimensional data matrix. Table 1 lists all the characteristic values.

The 8 index data reflecting the soil and water conservation situation are read into Matlab software as a multi-dimensional matrix, and the basic data must be first standardized. Then, enter the Matlab neural network toolbox, select the SOFM network, select hextop in the topology function, select linkdist in the distance function, set the learning rate to 0.1 , set the learning frequency to 2000 , set the learning rate to 0.02 during the adjustment stage, and set the neighborhood radius to 1.0 during the adjustment stage ${ }^{[11]}$. The number of neurons in the competition layer starts from $\mathrm{S}=2$ and then increases by 1 until $S=10$. From different classification results, considering the actual situation of soil and water conservation in Jinyun, when $S=2$ and $S=5$, the divided number of categories is significant. Therefore, using the two-level classification method, when $S=2$, Jinyun is divided into two first-level soil and water conservation divisions; when $\mathrm{S}=5$, Jinyun is divided into five secondlevel soil and water conservation divisions (Table 2).

Table 2. Regionalization table of soil and water conservation types in Jinyun

\begin{tabular}{|c|c|c|c|c|}
\hline \multicolumn{3}{|c|}{\begin{tabular}{|c|} 
Soil and Water \\
Conservation \\
Regionalization
\end{tabular}} & District & $\begin{array}{c}\text { Area } \\
/\left(\mathbf{k m}^{2}\right)\end{array}$ \\
\hline \multirow[b]{2}{*}{ I } & I-1 & $\begin{array}{l}\text { Center-Hill Basin- } \\
\text { Living Environment } \\
\text { Maintenance Zone }\end{array}$ & $\begin{array}{c}\text { Wuyun St., Xiandu St., } \\
\text { Xinbi St., Shuhong } \\
\text { Town }\end{array}$ & 205.46 \\
\hline & $\mathrm{I}-2$ & $\begin{array}{l}\text { North-Hill Basin- } \\
\text { Living Environment } \\
\text { and Water Quality } \\
\text { Maintenance Zone }\end{array}$ & $\begin{array}{l}\text { Dongfang Town, } \\
\text { Huzhen Town }\end{array}$ & 310.35 \\
\hline \multirow{3}{*}{ II } & II-1 & $\begin{array}{l}\text { East-Hill Mountain - } \\
\text { Ecological } \\
\text { Maintenance Zone }\end{array}$ & $\begin{array}{l}\text { Qianlu Township, Sanxi } \\
\text { Township, Rongiiang } \\
\text { Township, Shuangxikou } \\
\text { Township, Dayuan } \\
\text { Town, Huyuan } \\
\text { Township }\end{array}$ & 339.92 \\
\hline & II-2 & $\begin{array}{c}\text { Southeast- } \\
\text { Mountain-Water } \\
\text { Conservation Zone } \\
\end{array}$ & $\begin{array}{c}\text { Fangxi Township, } \\
\text { Shijian Township, } \\
\text { Dayang Town } \\
\end{array}$ & 228.54 \\
\hline & II-3 & $\begin{array}{l}\text { West-Hill Mountain- } \\
\text { Ecological } \\
\text { Maintenance Zone }\end{array}$ & $\begin{array}{c}\text { Xinjian Town, Qili } \\
\text { Township, Dongdu } \\
\text { Town } \\
\end{array}$ & 365.25 \\
\hline
\end{tabular}

When the first-level division is adopted, it is divided into two types of zones. The first is the Hilly BasinLiving Environment and Water Quality Maintenance Zone, located in the north-central part of Jinyun; the second is Hill Mountain-Water Conservation and Ecological Maintenance Zone, located in the southeast of Jinyun.

When the second-level partition is adopted, it is divided into five types of zones(Figure 1), and the characteristics of each type are as follows:

I-1 Center-Hilly Basin-Living Environment Maintenance Zone, this zone includes Wuyun Street, Xiandu Street, Xinbi Street, and Shuhong Town, with a land area of $205.46 \mathrm{~km}^{2}$. The regional topography is dominated by hills and basins. This zone is a concentrated area of residential, commercial, and industrial layout in Jinyun, with convenient transportation and developed economy. Therefore, the leading function of soil and water conservation is the maintenance of living environment. 
I-2 North-Hilly Basin-Living Environment and Water Quality Maintenance Zone, this zone includes Dongfang Town and Huzhen Town, with a land area of $310.35 \mathrm{~km}^{2}$. The regional topography is dominated by hills and basins, and Haoxi is the main river. This zone includes Huzhen Town, the sub-center of Jinyun, and Jinyun Industrial Park, so the leading functions of soil and water conservation are living environment and water quality maintenance.

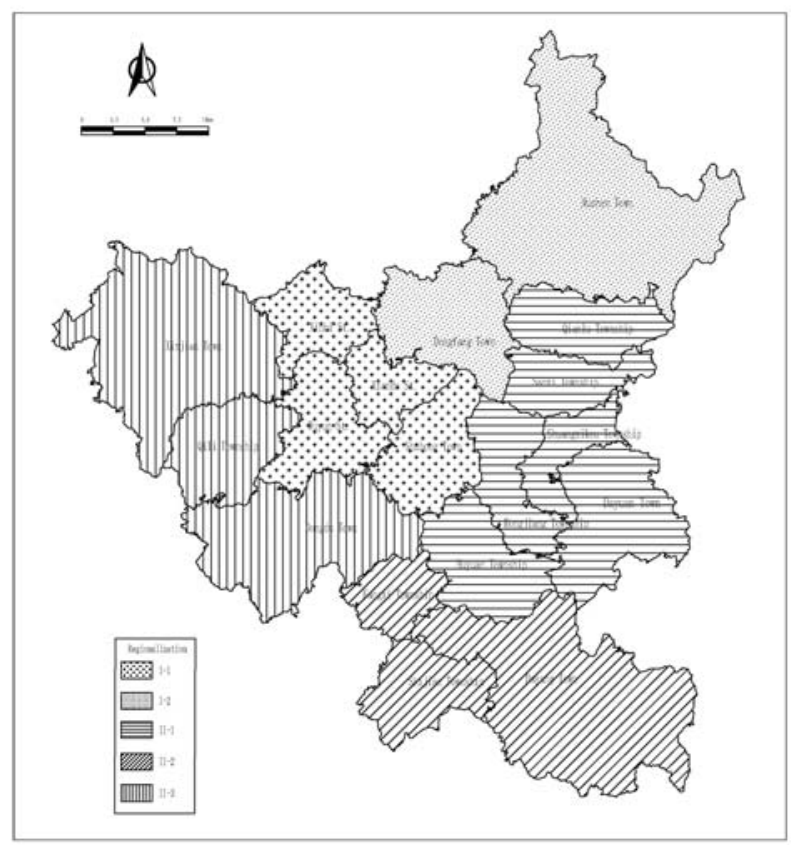

Fig. 1. Zoning map of soil and water conservation types

in Jinyun based on the SOFM network.

II-1 East-Hill Mountain -Ecological Maintenance Zone, this zone includes Qianlu Township, Sanxi Township, Rongjiang Township, Shuangxikou Township, Dayuan Township, and Huyuan Township, with a land area of $339.92 \mathrm{~km}^{2}$. The regional topography is dominated by hills and mountains. There are a large number of provincial ecological non-commercial forests in this zone. The natural ecological environment is excellent and the biological resources are rich. Therefore, the leading function of soil and water conservation is ecological maintenance.

II-2 Southeast-Mountain-Water Conservation Zone, this zone includes Fangxi Township, Shijian Township, and Dayang Town, with a land area of $228.54 \mathrm{~km}^{2}$. The regional topography is dominated by hills and mountains. There are drinking water sources such as Dayang Reservoir in this zone, so the leading function of soil and water conservation is water conservation.

II-3 West-Hill Mountain-Ecological Maintenance Zone, this zone includes Xinjian Town, Qili Township, and Dongdu Town, with a land area of $365.25 \mathrm{~km}^{2}$. The regional topography is dominated by hills and mountains. There are a large number of provincial ecological noncommercial forests in this zone. The natural ecological environment is excellent and the biological resources are rich. Therefore, the leading function of soil and water conservation is ecological maintenance.

\section{Conclusions}

(1) It is feasible to use the SOFM network model to classify the soil and water conservation regionalization. The two-level classification method is adopted, and the results are finally divided into 2 first-level types and 5 second-level types. The results reflect the leading functions of different water and soil conservation types.

(2) When constructing a classification indicator system, indicators are selected from multiple aspects such as natural conditions, socio-economic conditions, soil erosion characteristics, and the present state of soil and water conservation, to avoid errors caused by simply selecting a few indicators to affect the classification results, so that the classification results are more reasonable.

(3) The automatic classification method of the SOFM network model is simpler than the traditional mathematical classification method and more objective than the artificial classification method. The final division results also reflect the characteristics of soil and water conservation in various types of zones more clearly, indicating that the SOFM network model is an effective method for dividing soil and water conservation regionalization.

\section{References}

1. B. Wang, Y. Liu. Thoughts on the regionalization of the three-level of soil and water conservation in the northwest Loess Plateau[C]. 2012 Annual Meeting of the Planning and Design Commission of Chinese Soil and Water Conservation Society, Yangzhou.

2. J. Guan. Principles of Water and Soil Conservation [M]. Beijing: China Forestry Publishing, 1995.

3. S. Li, H. He, Z. Niu, et al. Regional soil and water conservation planning of Linhai City $[\mathrm{J}]$. Bulletin of Soil and Water Conservation, 2008, 2(28): 199 205.

4. L. Wang. Soil and Water Conservation[M]. Beijing: China Forestry Publishing, 2000.

5. Z. Wang, C. Wang. Problems of regionalization and planning of soil and water conservation in China[J]. Science of Soil and Water Conservation, 2007, 5(1): 105.

6. T. Kohonen. Self-Organizing Maps[M]. 2nd Edition Berlin Heidelberg, New York: Springer-Vedag, 1997.

7. M. Ye, Y. Wang, J. Peng, et al. Classification of land use degree in Yunnan province based on SOFM networks[J]. Progress in Geography, 2007, 26(2): 97-105.

8. J. Zhang, H. Yang. Application of self-organizing neural networks to classification of plant communities in Pangquangou Nature Reserve, North China[J]. Acta Ecologica Sinca, 2007, 27(3): 10051010.

9. B. Ni, L. Zhang, M. Yao. Clustering analysis based on SOFM network[J]. Computer Engineering and Design, 2006, 27(5): 855-856. 
10. J. Lin, M. Lin. Research in clustering of SOFM neural network $[\mathrm{J}]$. Modern Electronics Technique, 2006, 29(24) : 41-43.

11. K. Chen, Z. Liu, J. Li, et al. SOFM-based nutrient cycling classification of forest ecosystems in the Loess Plateau[J]. Acta Ecologica Sinica, 2011, 31(23): 7022-7030.

Table 1. Classification index of soil and water conservation regionalization in Jinyun

\begin{tabular}{|c|c|c|c|c|c|c|c|c|}
\hline $\begin{array}{l}\text { Name of } \\
\text { the } \\
\text { townships }\end{array}$ & $\begin{array}{c}\text { average } \\
\text { elevatio } \\
\mathbf{n} /(\mathbf{m})\end{array}$ & $\begin{array}{c}\text { relative } \\
\text { height } \\
\text { difference } \\
/(\mathbf{m}) \\
\end{array}$ & $\begin{array}{c}\text { gully } \\
\text { density/ } \\
\left(\mathbf{k m} / \mathbf{k m}^{2}\right)\end{array}$ & $\begin{array}{c}\text { population } \\
\text { density / } \\
\left(\text { person } / \mathbf{k m}^{2}\right)\end{array}$ & $\begin{array}{c}\text { per capita } \\
\text { disposabl } \\
\text { e income/ } \\
\text { (yuan) }\end{array}$ & $\begin{array}{c}\text { area ratio } \\
\text { of soil } \\
\text { erosion/ } \\
(\%) \\
\end{array}$ & $\begin{array}{c}\text { area ratio of } \\
\text { soil erosion } \\
\text { above } \\
\text { moderate/(\%) } \\
\end{array}$ & $\begin{array}{c}\text { vegetation } \\
\text { coverage/ } \\
(\%)\end{array}$ \\
\hline Wuyun St. & 303.75 & 377 & 0.0691 & 1625.22 & 21819 & 16.45 & 11.96 & 0.69 \\
\hline Xiandu St. & 523.85 & 839 & 0.0502 & 215.56 & 28164 & 23.72 & 18.23 & 0.6 \\
\hline Xinbi St. & 402.82 & 648 & 0.0421 & 1705.17 & 29400 & 14.63 & 8.61 & 0.61 \\
\hline $\begin{array}{c}\text { Xinjian } \\
\text { Town }\end{array}$ & 588.5 & 943 & 0.4180 & 396.59 & 21630 & 6.05 & 4.54 & 0.75 \\
\hline $\begin{array}{c}\text { Huzhen } \\
\text { Town }\end{array}$ & 688.07 & 1058 & 0.3286 & 354.59 & 26415 & 22.63 & 14.28 & 0.7 \\
\hline $\begin{array}{l}\text { Dongdu } \\
\text { Town }\end{array}$ & 521.13 & 880 & 0.0855 & 259.22 & 26388 & 9.28 & 7.76 & 0.7 \\
\hline $\begin{array}{c}\text { Shuhong } \\
\text { Town }\end{array}$ & 525.9 & 807 & 0.0785 & 287.38 & 6198 & 26.71 & 22.11 & 0.67 \\
\hline $\begin{array}{c}\text { Dongfang } \\
\text { Town }\end{array}$ & 551.84 & 841 & 0.0939 & 291.75 & 24321 & 23.14 & 17.02 & 0.72 \\
\hline $\begin{array}{c}\text { Dayuan } \\
\text { Town }\end{array}$ & 682.21 & 950 & 0.0982 & 254.20 & 14760 & 21.78 & 19.82 & 0.85 \\
\hline $\begin{array}{c}\text { Dayang } \\
\text { Town }\end{array}$ & 898.45 & 1169 & 0.3273 & 84.58 & 15630 & 12.67 & 10.81 & 0.78 \\
\hline $\begin{array}{c}\text { Qili } \\
\text { Township }\end{array}$ & 523.49 & 770 & 0.1106 & 304.40 & 18435 & 5.45 & 4.39 & 0.64 \\
\hline $\begin{array}{c}\text { Qianlu } \\
\text { Township } \\
\end{array}$ & 675.1 & 944 & 0.0617 & 163.37 & 15960 & 31.98 & 20.66 & 0.78 \\
\hline $\begin{array}{l}\text { Huyuan } \\
\text { Township }\end{array}$ & 710.08 & 972 & 0.0825 & 229.04 & 16680 & 35.85 & 30.43 & 0.72 \\
\hline $\begin{array}{l}\text { Shuangxiko } \\
\text { u Township }\end{array}$ & 602.63 & 708 & 0.0679 & 334.83 & 18300 & 19.91 & 17.07 & 0.82 \\
\hline $\begin{array}{l}\text { Rongjiang } \\
\text { Township }\end{array}$ & 634.01 & 837 & 0.0669 & 303.58 & 15234 & 16.58 & 14.84 & 0.7 \\
\hline $\begin{array}{c}\text { Sanxi } \\
\text { Township } \\
\end{array}$ & 658.13 & 746 & 0.0487 & 180.41 & 18927 & 13.72 & 11.30 & 0.82 \\
\hline $\begin{array}{c}\text { Fangxi } \\
\text { Township }\end{array}$ & 575.5 & 793 & 0.0817 & 130.20 & 16200 & 11.62 & 10.41 & 0.77 \\
\hline $\begin{array}{c}\text { Shijian } \\
\text { Township }\end{array}$ & 708.59 & 897 & 0.0662 & 142.32 & 17580 & 14.06 & 12.80 & 0.78 \\
\hline
\end{tabular}

